\title{
Augmented Reality Applied to Card Games
}

\author{
Hidehiko Okada and Hiroki Arakawa \\ Kyoto Sangyo University \\ Japan
}

\section{Introduction}

Applications of computer technologies to various entertainments have been researched, known as "entertainment computing" (e.g., kinds of researches have been reported in annual international conferences on this topic, ICEC (Stephane \& Jerome, 2009; Scott \& Shirley, 2008; Ma et al., 2007)). The aim of our research is to evaluate the effectiveness of augmented reality (AR) user interface for playing card games. Players of a card game need to know rules of the game, so beginners cannot play by themselves until they learn the rules well (or, need help from experienced players). Our idea to solve this problem is a computer system with AR user interface which intuitively guides game plays in the beginners' view. The authors expect that the system enables a beginner to play games even if $\mathrm{s} /$ he does not know rules well and learn the rules as s/he plays games with the system (i.e., learn by their game experiences). The authors have been applying our idea to card games and evaluated the effectiveness by experiments with beginner players. In this chapter, the authors report two examples: AR applied to Mate and Bohemian Schneider. These games are selected because the games are relatively minor in Japan (compared with, e.g., poker) and many of us are beginners of the games.

\section{AR applied to Mate}

\subsection{Game rules}

Mate games are played by two players. Twenty cards are used in Mate games: five pieces \{ A, K, Q, 10 and 7 \} of the four suits \{hearts, diamonds, spades and 20 cards are dealt to the two players, 10 for each. A round includes 10 turns or less. In each turn, a player first opens any card (threat), and then the opponent must open a card that can counter the threat: if the opponent doesn't have any card that can counter the threat, the opponent loses the round. The rules to counter the threat are:

1. if $\mathrm{s} /$ he has one or more cards of which the suit is the same as the threat (e.g., $\mathbf{s}), \mathrm{s} / \mathrm{he}$ must open a card among them,

2. else if $\mathrm{s} /$ he has one or more cards of which the piece is the same as the threat (e.g., $\mathrm{K}$ ), $\mathrm{s} /$ he must open a card among them.

Who opened a card with a higher rank takes initiative in the next turn. Card ranks are as follows.

- $\quad$ Suit ranks (from the highest to the lowest): $\mathbf{\infty}, \mathbf{s}, \mathbf{v}, \mathbf{}$.

- $\quad$ Piece ranks (from the highest to the lowest): A, 10, K, Q, 7. 
If both of the two players opened all the 10 cards, the round is a draw. The winner player of a round gains $t * s$ points where $t$ denotes the number of turns in which the player won the round and $\mathrm{s}$ denotes the score of the threat piece with which the player won the round. Piece scores are shown in Table 1. For example, if a player wins a round in the five turns with $\vee K$, the player gains $20(=5 * 4)$ points. For more details, see a reference book, e.g., (Sackson, 1992).

\begin{tabular}{|c|c|c|}
\hline Piece & Rank & Score \\
\hline $\mathrm{A}$ & 1 & 11 \\
\hline $\mathrm{K}$ & 3 & 4 \\
\hline $\mathrm{Q}$ & 4 & 3 \\
\hline 10 & 2 & 10 \\
\hline 7 & 5 & 7 \\
\hline
\end{tabular}

Table 1. Peace ranks and scores in Mate

A Mate beginner will become able to play games by her/himself after s/he learns:

- which card s/he can open to counter the threat,

- which card s/he should open as the threat to win the round, and

- $\quad$ which card s/he should open as the threat to take initiative in the next turn.

Our system should therefore make augmentations appropriately so that a beginner can easily learn these factors.

\subsection{System configuration}

Fig. 1 shows the configuration of our system. Cards opened by players in a game and the deal of a beginner player are continuously captured at a specific frame rate and recognized. CGs for guiding the beginner (e.g., which card in her/his deal is recommended to open) are generated and overlapped to the webcam-captured screen. This system configuration is consistently employed in our card game applications.

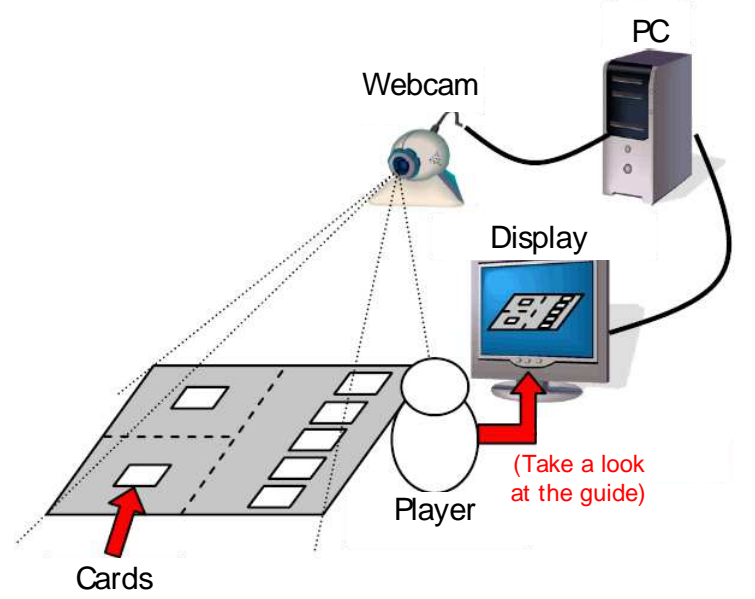

Fig. 1. Configuration of our system 


\subsection{Visual augmentations for beginners}

This section illustrates how our system augments the player's view of cards. Fig. 2 shows an example of the webcam screen. Fig. 2(a) is a captured raw screen and Fig. 2(b) is a screen augmented by our software program. The program utilized ARToolkit ${ }^{1}$ (Kato \& Billinghurst, 1999) for the processes of card recognition and CG augmentation. The authors designed paper cards with bold black frame prints to use each card as an ARToolkit marker.

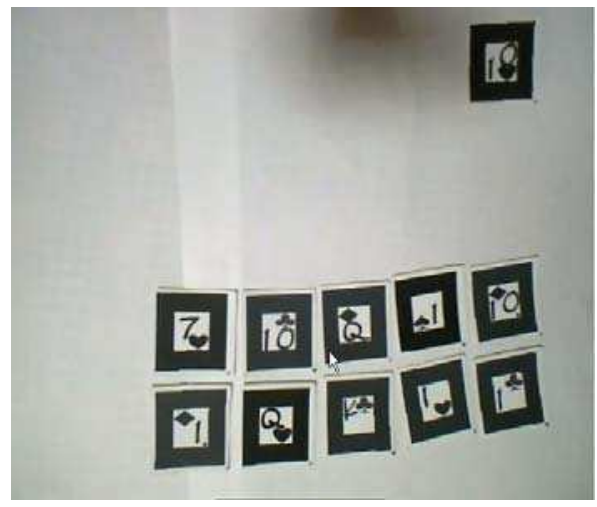

(a) Raw

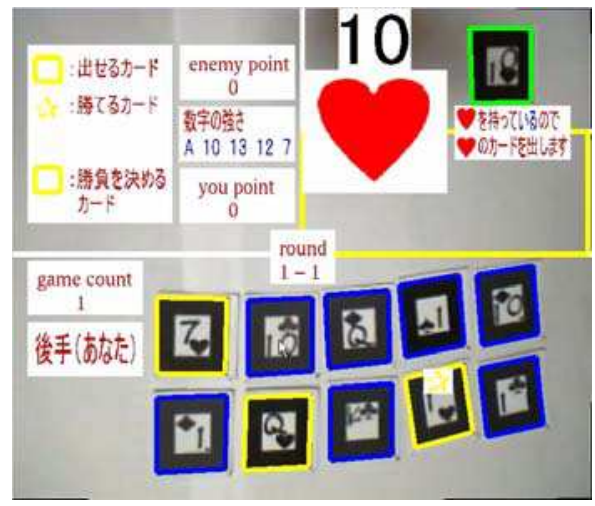

(b) Augmented

Fig. 2. Example of webcam screen by our system (the user is to counter the threat)

In this example, the user is to counter the threat opened by the opponent player. The system guides the player to open either of the three s $_{\mathrm{s}}$ in her/his deal (where the 10 cards in the deal are shown in the lower area of the screen), because the threat card is $\$ 10$. The system augments the webcam screen as follows.

- The threat card is marked with a green frame.

- The recognized suit and piece of the threat card is shown near the card. In the example of Fig. 2(b), the threat card is recognized as $\vee 10$.

${ }^{1}$ http:/ / www.hitl.washington.edu/artoolkit (last accessed: 10/06/2009). 
- Cards in the player's deal that can counter the threat are marked as yellow frames. In Fig. 2(b), three cards are marked $(\vee 7, \vee Q$ and $\vee 1)$.

- A card in the player's deal with a higher rank than the threat is marked with a yellow star. The card is a recommended one to open in this turn. In Fig. 2(b), $\$ 1$ is marked with a yellow star because Ace is ranked higher than 10. By countering the $\$ 10$ threat with $\checkmark 1$, the player can win the current turn and take initiative in the next turn.

- A message for navigating the player which cards are able to open now is briefly shown (in Japanese). In Fig. 2(b), the message shown in the upper-right area (just below the threat card) says "please open a $\vee$ card because you have $\vee$ s". From the message and the display of the recognized suit \& piece of the threat card, the player will learn that $\mathrm{s} /$ he can open a card of which the suit is the same as the card the opponent player opened first.

Fig. 3 shows another example of the augmented webcam screen. In this example, the user of the system is to open a card in her/his deal as the threat to the opponent player. In this case, the user can open any card in her/his deal (no constraints for the threat): the system shows this by marking all cards in her/his deal with yellow frames. In addition, the system marks one or more recommended cards with yellow stars: in Fig. $3, \downarrow 1$ and $\downarrow 1$ are the recommended ones. In the cases where the user has one or more cards with which the user can win the round (i.e., the opponent cannot counter if the user opens one of the cards as the threat), the system marks them with blinked yellow frames and guides the user with a brief message on the brink-marked cards.

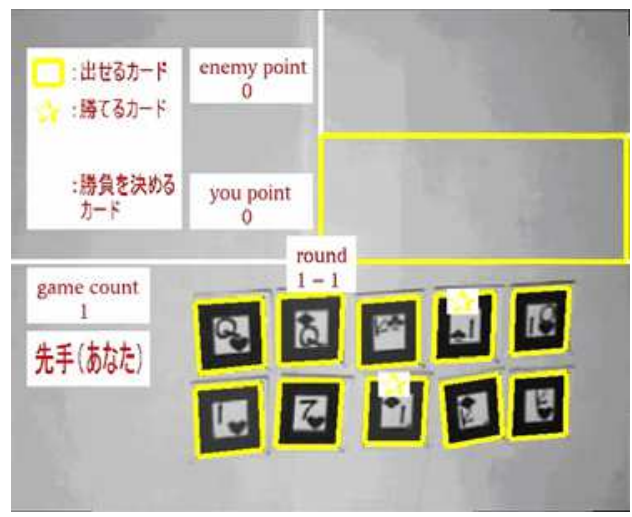

Fig. 3. Example of augmented screen (the user is to open a card as the threat)

Note that the authors do not intend to enable a player to cheat by using our system: the system does not tell what the user cannot know even if the user is an experienced. The system neither captures the deal of the opponent player nor shows them to the user.

\subsection{Evaluation}

To evaluate the effectiveness of our idea, the authors had an experiment with Mate beginners. Each beginner played six rounds of Mate games against an experienced player. In the 1st-4th rounds each beginner played with our system, and in the 5th-6th rounds the beginner played without our system. The experienced player always played games without the system. Thus, the ability of our system for (i) guiding a beginner with no rule knowledge 
and (ii) helping a beginner learn game rules while playing under the AR guides, can be evaluated by the performances of the beginners in (i) the first four rounds and (ii) the next two rounds respectively.

The experiment took 1.0-1.5 hours per beginner. After the six rounds, each beginner was asked to assess five-scale subjective satisfactions on questionnaire items.

Five university students participated in this experiment where four of them were beginners with no prior knowledge/experience on Mate and the other was an experienced.

The rate of turns in which the beginner opened a higher-ranked card per round ("winning turn rate") is a measure for the system ability. The time per beginners' turn (i.e., how long a beginner took to open a card in a turn: "turn time"), is also a measure. The winning turn rate and the turn time were measured from game logs recorded by our software program.

Table 2 shows the mean winning turn rate and the mean turn time over the four beginners. Even though the beginners knew no Mate rule before the experiments, in the first four rounds they could play games appropriately and win more than a half $(64 \%)$ of the turns with our system. This result indicates the above-mentioned ability (i) of the system. Besides, even though the beginners played without our system in the last two rounds, they could play games by themselves and win nearly a half $(48 \%)$ of the turns, i.e., they could play games evenly against the experienced player. In a case where a player opens a card randomly in each turn, the winning turn rate of $50 \%$ cannot be expected because of the rule constraints. Thus, the result indicates the above-mentioned ability (ii) of the system.

On the contrary, Table 2 shows that the mean turn time for the rounds without the system was relatively greater than that with the system: the beginners took relatively longer to decide which card to open after they stopped using the system. This result indicates that the beginners did not become familiar enough to make quick decisions within the first four rounds. But, compared with the mean turn time by the experienced player $(18.0 \mathrm{sec})$, it can be said that the beginners didn't take so much time $(20.9 \mathrm{sec})$ even after they stopped using the system. Future work is required to investigate whether the mean turn time in the "testing" rounds becomes shorter as a beginner plays more "learning" rounds.

\begin{tabular}{|l|c|c|}
\cline { 2 - 3 } \multicolumn{1}{c|}{} & Rate & Time \\
\hline 1st-4th rounds with our system & $64 \%$ & $13.8 \mathrm{sec}$ \\
\hline 5th-6th rounds without our system & $48 \%$ & $20.9 \mathrm{sec}$ \\
\hline
\end{tabular}

Table 2. Mean winning turn rate and mean turn time over four beginners

Mean scores of the five-scale subjective ratings are shown in Table 3. The beginners felt our system was useful (mean score of 4.25 for the questionnaire item \#4), which supports our idea.

\begin{tabular}{|ll|r|}
\hline \multicolumn{1}{|c|}{ Questionnaire } & \multicolumn{1}{c|}{$\begin{array}{c}\text { Mean score } \\
\text { (Best=5, Worst=1) }\end{array}$} \\
\hline 1. & Easy to read screen. & 4.00 \\
\hline 2. & Easy to understand meanings of graphical guides. & 4.50 \\
\hline 3. & $\begin{array}{l}\text { Easy to make decisions (the amount of time } \\
\text { required for making decisions is small). }\end{array}$ & 3.00 \\
\hline 4. & Useful. & 4.25 \\
\hline 5. & Fun. & 3.25 \\
\hline
\end{tabular}

Table 3. Subjective ratings by beginners 


\section{AR applied to Bohemian Schneider}

\subsection{Game rules}

Bohemian Schneider is a trick-taking game by two players. Thirty-two cards are used: eight pieces $\{A, K, Q, J, 10,9,8$ and 7$\}$ of the four suits $\{\boldsymbol{\varphi}, \downarrow$ and $\boldsymbol{\imath}\}$. First, six cards are dealt to each player respectively and the rest are left as stock. A player (P1) first and the opponent (P2) next opens a card in her/his deal respectively.

- If P2 opens a card of the next rank to the card by P1, P2 wins the turn and gains $x$ points, where $x$ is the score associated to the card with which $\mathrm{s} /$ he wins the turn. Card ranks and scores are shown in Table 4. There are two variations: suit must be the same or not. For example, suppose P1 opens $\$ 10$. In the former case, P2 can win with $\vee$ J only. In the latter case, P2 can win with any of $\{\vee \mathrm{J}, \downarrow \mathrm{J}, \boldsymbol{J}$ and $\$ \mathrm{~J}\}$. The former is the original, but the latter was employed in our application because beginners will play games easier under the latter rule. Thus, for example, if P1 leads with K and P2 follows with Ace then P2 gains 11 points.

- Else, P2 can open any card in her/his deal. P1 wins the turn and gains $x$ points in the same manner.

The winner of the last turn and the other draw a card from the stock respectively (the winner first), and the winner leads the next turn. A game consists of 16 turns. The winner of a game is the player who gains the points more in the 16 turns. For more details, see a reference book, e.g., (Parlett, 2009).

\begin{tabular}{|c|c|c|}
\hline Piece & Rank & Score \\
\hline $\mathrm{A}$ & 1 & 11 \\
\hline $\mathrm{K}$ & 2 & 4 \\
\hline $\mathrm{Q}$ & 3 & 3 \\
\hline $\mathrm{J}$ & 4 & 2 \\
\hline 10 & 5 & 10 \\
\hline 9 & 6 & 0 \\
\hline 8 & 7 & 0 \\
\hline 7 & 8 & 0 \\
\hline
\end{tabular}

Table 4. Peace ranks and scores in Bohemian Schneider

A beginner of Bohemian Schneider will become able to play games by her/himself after s/he learns:

- the card ranks,

- the card scores,

- a card of the next rank is required to win a turn, and

- the winner of the last turn can take initiative in the next turn.

\subsection{Visual augmentations for beginners}

Fig. 5 shows an example of the augmented webcam screen. In this figure, the six cards in the lower area are the deal of the user of our system, and the card in the upper left area (in this case 10 ) is the card opened first by the opponent player. The user is to follow to 10 with a card in her/his deal. In the example of Fig.5, our system guides the user to open $\$ \mathrm{~J}$ (to move \&J to the upper right area) because $\mathrm{J}$ is the only peace to beat 10 . The system shows messages 
in the lower left area: "now it's your turn", "the yellow-marked card is recommended", and "only J can beat 10; open any if no J in your deal," in Japanese. Such messages as the third one in this example will help a user learn the rank relations of card pairs.

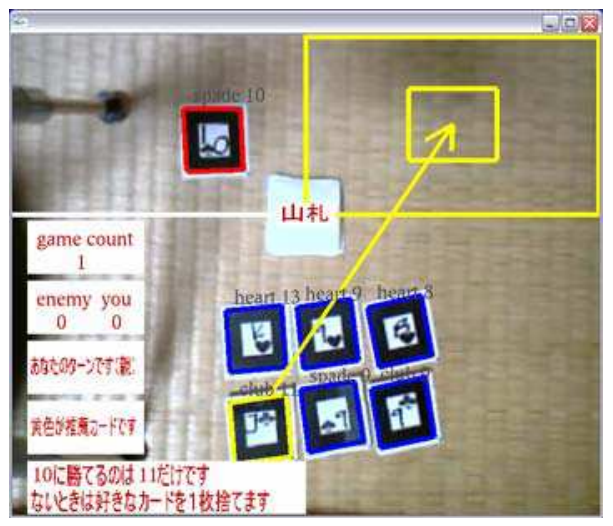

Fig. 5. Example of augmented screen (the user is to open a card second in a turn)

Fig. 6 shows another example in which the user is to open a card first in a turn. In this example, our system guides the user to open $\vee$ A (because the user can win this turn with Ace and thus can take initiative again in the next turn). The system shows messages in the lower left area: "now it's your turn", "the yellow-marked card is recommended", and "you lose this turn if the opponent opens a card of next higher-ranked than yours, else you win." In addition, the card ranks are shown in the lower right area.

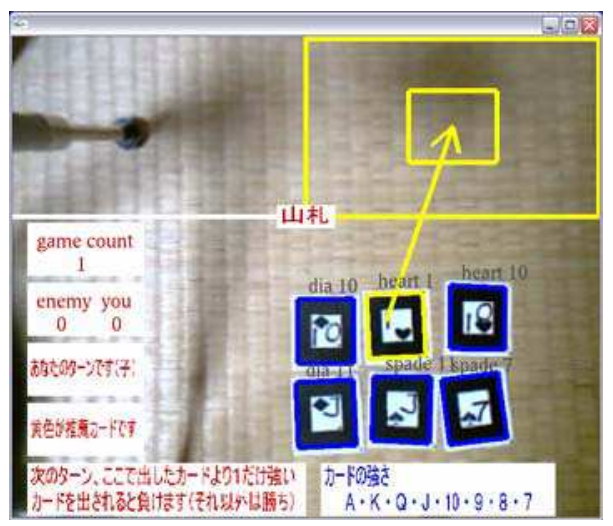

Fig. 6. Example of augmented screen (the user is to open a card first)

Fig. 7 shows another example in which the result of the current turn is displayed after both players opened their cards. In this example, the user first opened $\vee$ A (the card in the upper right area) and the opponent followed with $\vee \mathrm{Q}$ (the card in the upper left area). The system shows, in the lower left message area, "you gained 11 points because you won this turn with Ace." The card scores are also displayed in the lower right area, which will help the user learn the scores. 


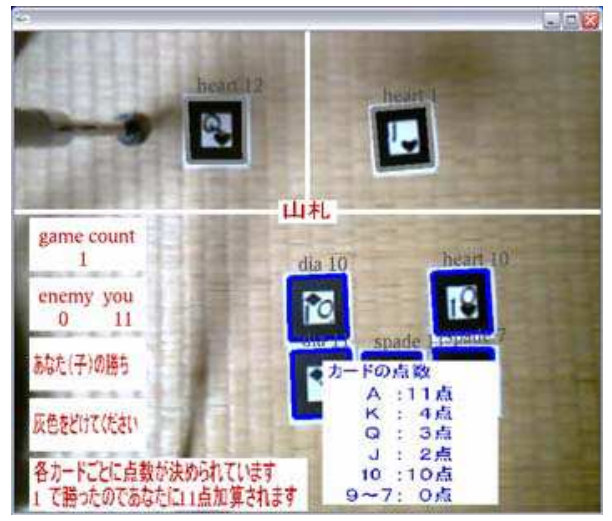

Fig. 7. Example of augmented screen (display of a turn result)

Fig. 8 shows another example in which the system prompts to draw a card from the stock. The stock is located in the center of the screen. The system shows that, in the lower left message area, the winner of the last turn draws first and lead the next turn.

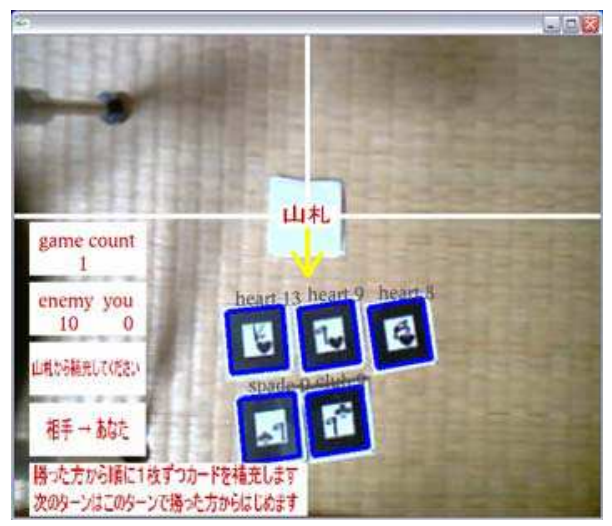

Fig. 8. Example of augmented screen (prompt to draw a card from the stock)

\subsection{Evaluation}

The authors had an experiment with beginners of Bohemian Schneider, in the same manner as the experiment for the Mate application. Each beginner played three rounds of games against an experienced player. In the 1st and 2nd rounds each beginner played with our system, and in the 3rd rounds the beginner played without our system. The experienced player always played games without the system. The ability of our system is evaluated by the performances of the beginners in the first two rounds and the third round respectively. After the three rounds, each beginner was asked to assess five-scale subjective satisfactions on five questionnaire items.

Five university students participated in this experiment where four of them were beginners with no prior knowledge/experience on Bohemian Schneider and the other was an experienced.

Table 5 shows the mean winning turn rate and the mean turn time over the four beginners. 
The beginners could win more than a half $(57 \%)$ of the 32 turns in the 1st and 2nd rounds, being guided by our system. This indicates the beginners could play games well against the experienced even though they did not know the game rules. However, in the 3rd round, without our system they could win much less than a half $(28 \%)$ of the 16 turns. This indicates, inconsistently with our expectation, they could not learn the rules enough while they played with our system. The reasons of this result will be that, the amount of "learning" turns was not enough for beginners to learn from their experiences, and improvements in the guidance of our system are required for better learning. The mean turn time for the rounds without the system was greater than that with the system, but the difference was much smaller than that in the Mate experiment. Again, in our future work the authors should investigate whether more "learning" rounds actually contribute to improve beginner performances in "testing" rounds.

\begin{tabular}{|l|c|c|}
\cline { 2 - 3 } \multicolumn{1}{c|}{} & Rate & Time \\
\hline 1st and 2nd rounds with our system & $57 \%$ & $6.96 \mathrm{sec}$ \\
\hline 3rd round without our system & $28 \%$ & $8.84 \mathrm{sec}$ \\
\hline
\end{tabular}

Table 5. Mean winning turn rate and mean turn time over four beginners

Mean scores of the five-scale subjective ratings are shown in Table 6. The beginners felt our system was very useful (mean score of 4.75 for the questionnaire item \#4), which again supports our idea.

\begin{tabular}{|ll|r|}
\hline \multicolumn{1}{|c|}{ Questionnaire } & \multicolumn{2}{c|}{$\begin{array}{c}\text { Mean score } \\
\text { (Best=5, Worst=1) }\end{array}$} \\
\hline 1. & Easy to read screen. & 3.50 \\
\hline 2. & Easy to understand meanings of graphical guides. & 4.25 \\
\hline 3. & $\begin{array}{l}\text { Easy to make decisions (the amount of time } \\
\text { required for making decisions is small). }\end{array}$ & 4.25 \\
\hline 4. & Useful. & 4.75 \\
\hline 5. & Fun. & 3.75 \\
\hline
\end{tabular}

Table 6 . Subjective ratings by beginners

\section{Conclusion}

The authors applied augmented reality (AR) user interface to the card games, Mate and Bohemian Schneider. The applications aim to help beginner players play games by themselves and learn the rules as they play games (i.e., enable experience-based learning). Our system visually augments the player's view of cards so that the player can make decisions on her/his actions (e.g., which card to open at each turn). Effectiveness of our idea was evaluated by experiments with four beginners. Based on the results of the winning turn rate, the turn time and the subjective assessments, it was partially confirmed that our system contributes to help beginners play games and learn rules, but required in our future work are additional experiments with more players and more rounds, more investigations on effective augmentation methods, and applications of our idea to other games. 


\section{References}

Kato, H. \& Billinghurst, M. (1999). Marker Tracking and HMD Calibration for a Video-Based Augmented Reality Conferencing System. Proceedings of the 2nd International Workshop on Augmented Reality (IWAR 99), pp. 85-94

Ma, L.; Rauterberg, M. \& Nakatsu, R. (Eds.) (2007). Entertainment Computing - ICEC 2007, Lecture Notes in Computer Science, Vol. 4740, Springer

Parlett, D. (2009). The Penguin Book of Card Games, Penguin Group USA

Sackson, S. (1992). A Gamut of Games, Dover Publications

Scott, M. S. \& Shirley, S. (Eds.) (2008). Entertainment Computing - ICEC 2008, Lecture Notes in Computer Science, Vol. 5309, Springer

Stephane, N. \& Jerome, D. (Eds.) (2009). Entertainment Computing - ICEC 2009, Lecture Notes in Computer Science, Vol. 5709, Springer 


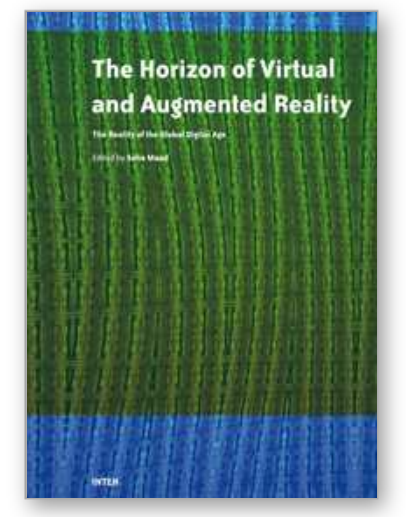

\author{
Augmented Reality \\ Edited by Soha Maad
}

ISBN 978-953-7619-69-5

Hard cover, 230 pages

Publisher InTech

Published online 01, January, 2010

Published in print edition January, 2010

Virtual Reality (VR) and Augmented Reality (AR) tools and techniques supply virtual environments that have key characteristics in common with our physical environment. Viewing and interacting with 3D objects is closer to reality than abstract mathematical and 2D approaches. Augmented Reality (AR) technology, a more expansive form of VR is emerging as a cutting-edge technology that integrates images of virtual objects into a real world. In that respect Virtual and Augmented reality can potentially serve two objectives: reflecting realism through a closer correspondence with real experience, and extending the power of computer-based technology to better reflect abstract experience. With the growing amount of digital data that can be stored and accessed there is a rising need to harness this data and transform it into an engine capable of developing our view and perception of the world and of boosting the economic activity across domain verticals. Graphs, pie charts and spreadsheet are not anymore the unique medium to convey the world. Advanced interactive patterns of visualization and representations are emerging as a viable alternative with the latest advances in emerging technologies such as AR and VR. And the potential and rewards are tremendous. This book discusses the opportunities and challenges facing the development of this technology.

\title{
How to reference
}

In order to correctly reference this scholarly work, feel free to copy and paste the following:

Hidehiko Okada and Hiroki Arakawa (2010). Augmented Reality Applied to Card Games, Augmented Reality, Soha Maad (Ed.), ISBN: 978-953-7619-69-5, InTech, Available from:

http://www.intechopen.com/books/augmented-reality/augmented-reality-applied-to-card-games

\section{INTECH}

open science | open minds

\section{InTech Europe}

University Campus STeP Ri

Slavka Krautzeka 83/A

51000 Rijeka, Croatia

Phone: +385 (51) 770447

Fax: +385 (51) 686166

www.intechopen.com

\section{InTech China}

Unit 405, Office Block, Hotel Equatorial Shanghai

No.65, Yan An Road (West), Shanghai, 200040, China 中国上海市延安西路65号上海国际贵都大饭店办公楼405单元

Phone: +86-21-62489820

Fax: +86-21-62489821 
(C) 2010 The Author(s). Licensee IntechOpen. This chapter is distributed under the terms of the Creative Commons Attribution-NonCommercialShareAlike-3.0 License, which permits use, distribution and reproduction for non-commercial purposes, provided the original is properly cited and derivative works building on this content are distributed under the same license. 